\title{
Platelet Hyperaggregation and Increased Plasma Level of Von Willebrand Factor in Diabetics with Retinopathy* **
}

\author{
D. Bensoussan, S. Levy-Toledano***, P. Passa, J. Caen and J. Canivet**** \\ Dept. of Endocrinology and of Haemostasis and Experimental Thrombosis, University Paris-VII, Hopital Saint Louis, Paris, France
}

Received: January 30, 1975, and in revised form: May 20, 1975

\begin{abstract}
Summary. In 18 insulin-dependent diabetics (6 without retinopathy, 6 with proliferative retinopathy and 6 with proliferative retinopathy treated by hypophysectomy) matched for age and duration of diabetes, in vitro haemostasis was studied using ADP induced platelet aggregation, ristocetin induced platelet aggregation which allows von Willebrand factor (VIII VWF) assay, and determination of antihemophilic factor procoagulant activity (VIII AHF). Using gel filtration-isolated platelets, the ADP induced hyperaggregation previously reported in diabetics with severe retinopathy untreated by hypophysectomy appeared to be related to a platelet and not a
\end{abstract}

plasma factor; the normal results of thrombin induced aggregation suggests that the presumed abnormal platelet factor is related to the platelet plasma membrane. High level of plasma VIII VWF was observed in diabetics with proliferative retinopathy while the VIII AHF level was within normal limits.

Key words: Diabetes, retinopathy, hypophysectomy, ADP induced platelet aggregation, ristocetin induced platelet aggregation, Von Willebrand factor, antihemophilic procoagulant factor.
Platelet hyperaggregation induced in vitro by low doses of adenosine-diphosphate (ADP) and decrease in the rate of disaggregation have been reported in diabetics with severe retinopathy $[1-3]$; this abnormality has not been observed in diabetics without retinopathy $[1,3]$, and has not been noticed in diabetics with severe retinopathy treated by hypophysectomy [3]. The present study using platelets isolated by gel filtration was undertaken to determine if the factor enhancing the ADP-induced hyperaggregation in diabetics lies in the plasma or in the platelets.

On the other hand a plasma factor necessary for ristocetin-induced platelet aggregation [4] and deficient in Von Willebrand's disease has been recently reported; a quantitative assay of this "Von Willebrand factor" (VIII VWF) has been described using platelet aggregation induced by ristocetin $[5,6]$. In this study we have determined the VIII VWF plasma level in diabetics. As the VIII VWF and the VIII clotting factor (VIII AHF) activities are carried by 2 subunits of the same molecule $[5,6]$, the VIII AHF assay was also performed and the VWF : AHF ratio was calculated.

\footnotetext{
* Supported by a grant from the Institut National de la Santé et de la Recherche Médicale (I.N.S.E.R.M.)

** Presented in part at the EASD 10th Annual Meeting, Jerusalem, 1974

*** Chargée de Recherche au C.N.R.S.

**** Reprint requests: J. Canivet, Department of Endocrinology, Hopital Saint Louis, 75475 Paris Cedex 10, France.
}

\section{Materials and Methods}

\section{A. Patients}

Three groups of 6 insulin-dependent diabetics matched for age and duration of diabetes (Table 1) were studied:

- group I: 6 patients of average age 41 years (range 22 to 60 years), of mean duration of diabetes 15 years (range 4 to 22 years), without retinopathy (that is with a normal ocular fundus after careful ophthalmoscopic examination and fluorescein angiography).

- group II: 6 patients of average 40 years (range 18 to 60 years), of mean duration of diabetes 17 years (range 6 to 25 years), with proliferative retinopathy (that is with new vessels in one or both eyes).

- group III: 6 patients of average age 43 years (range 27 to 57 years), of mean duration of diabetes 21 years (range 17 to 25 years), having undergone surgical hypophysectomy for proliferative retinopathy.

\footnotetext{
Abbrevations used in this paper:

PRP: platelet rich plasma

PPP: platelet poor plasma

GFP: gel filtered platelets

VWF or VIII VWF: Von Willebrand factor associated with factor VIII molecule

AHF or VIII AHF: antihemophilic factor procoagulant activity
} 
Table 1. Sex, age and duration of diabetes in the three groups of diabetics

\begin{tabular}{|c|c|c|c|c|c|c|c|c|c|c|c|}
\hline \multicolumn{4}{|c|}{ Group I } & \multicolumn{4}{|c|}{ Group II } & \multicolumn{4}{|c|}{ Group III } \\
\hline Cases & Sex & $\begin{array}{l}\text { Age } \\
\text { (years) }\end{array}$ & $\begin{array}{l}\text { Duration of } \\
\text { diabetes } \\
\text { (years) }\end{array}$ & Cases & Sex & $\begin{array}{l}\text { Age } \\
\text { (years) }\end{array}$ & $\begin{array}{l}\text { Duration of } \\
\text { diabetes } \\
\text { (years) }\end{array}$ & Cases & Sex & $\begin{array}{l}\text { Age } \\
\text { (years) }\end{array}$ & $\begin{array}{l}\text { Duration of } \\
\text { diabetes } \\
\text { (years) }\end{array}$ \\
\hline 1 & $\mathrm{~F}$ & 22 & 4 & 7 & $\mathrm{~F}$ & 35 & 17 & 13 & $\mathbf{M}$ & 34 & 21 \\
\hline 2 & $\mathrm{M}$ & 40 & 15 & 8 & M & 60 & 25 & 14 & M & 50 & 25 \\
\hline 3 & M & 25 & 10 & 9 & M & 55 & 21 & 15 & $F$ & 27 & 25 \\
\hline 4 & M & 50 & 20 & 10 & M & 45 & 18 & 16 & $\mathrm{~F}$ & 57 & 21 \\
\hline 5 & $\mathrm{~F}$ & 60 & 22 & 11 & M & 25 & 15 & 17 & $\mathrm{M}$ & 43 & 17 \\
\hline 6 & $\mathrm{M}$ & 50 & 18 & 12 & $\mathrm{M}$ & 18 & 6 & 18 & M & 45 & 18 \\
\hline Mean & & 41 & 15 & Mean & & 40 & 17 & Mean & & 43 & 21 \\
\hline
\end{tabular}

The tests were carried out with control subjects selected from a group of blood donors of the same sex and age.

\section{B. Methods}

a) Preparation of platelet-rich plasma (PRP), platelet-poor plasma (PPP) and gel-filtered platelets (GFP). For the preparation of PRP, 9 volumes of blood were withdrawn from the antecubital vein into plastic tubes containing 1 volume of $3.8 \% \mathrm{w} / \mathrm{v}$ sodium citrate; the mixture was centrifuged at $90 \mathrm{~g}$ for $10 \mathrm{~min}$ at $15^{\circ} \mathrm{C}$. After decanting the PRP, the PPP was prepared by centrifugation at $27500 \mathrm{~g}$ for $20 \mathrm{~min}$ at $10^{\circ} \mathrm{C}$, using a Sorvall RC $2 \mathrm{~B}$ centrifuge. The PRP from each patient and from each control subject was reconstituted to the same platelet count by dilution with autologous PPP.

For the preparation of isolated platelets, 9 volumes of blood were withdrawn into plastic tubes containing 1 volume of $\mathrm{ACD}(0.8 \%$ citric acid; $2.2 \%$ sodium citrate; $2.45 \%$ dextrose); gel-filtration on Sepharose $2 \mathrm{~B}$ was carried out according to a modification [7] of the method of Tangen et al. [8].

Isolation of platelets was necessary for determining if the ADP-induced hyperaggregation was dependent on a plasma or on a platelet factor. Therefore in a first experiment GFP from control subjects were added to PPP from diabetic patients; in a second experiment GFP aggregation rate in control subjects and in diabetics was measured in the absence of PPP, and the following cofactors were then used [7]: $0.05 \mathrm{ml}$ of gamma-globulins (from a $16 \mathrm{mg} / \mathrm{ml}$ solution), $0.05 \mathrm{ml}$ of human fibrinogen (from a $10 \mathrm{mg} / \mathrm{ml}$ solution) and calcium chloride at a final concentration of $2 \cdot 10^{-3} \mathrm{M}$.

b) Platelet aggregation. The determination was carried out by the photometric method of Born [9] using an aggregometer at $37^{\circ} \mathrm{C}$ with constant stirring. Two types of aggregometer were used: 1) the Born aggregometer MK 3 for the study of the PRP where the final volume in the tube was $1 \mathrm{ml}$, to which $10 \mu \mathrm{l}$ of the aggregation inducing agent were added; 2) the Born mini-aggregometer for the study of the GFP where the final volume in the tubes was $0.2 \mathrm{ml}$, consisting of 0.1 $\mathrm{ml}$ of GFP and $0.1 \mathrm{ml}$ of PPP, to which $10 \mu \mathrm{l}$ of the aggregation inducing agent were added.

Two methods were used for the platelet aggregation determination. In one the ratewas calculated by measuring the tangent of the curve at the maximum of its slope during the first $30 \mathrm{sec}$; in the other the intensity (fall of optical density) was obtained by measuring the height of the curve 2 min after addition of the inducer. Rate and intensity values were expressed as a percentage: the differences in optical density (O.D.) between the PRP and the corresponding PPP or the GFP + PPP and blank + PPP were arbitrarily designated as $100 \%$.

Platelet aggregation was determined in the presence of three inducers: 1) ADP (Sigma) at a final concentration of $2.5 \times 10^{-6} \mathrm{M}$ for the GFP aggregation, 2) Thrombin (Roche) at a final concentration of 0.2 units $/ \mathrm{ml}$ for the PRP aggregation, and of 0.03 units/ml for the GFP aggregation, 3) Ristocetin (Lundbaeck) at a final concentration of $1000 \mu \mathrm{g} / \mathrm{ml}$ for both PRP and GFP aggregation.

c) VWF assay. This determination was carried out with the method described by Weiss et al. [6], but in order to avoid the centrifugations and resuspensions from the 4 washings during the platelet preparation, the following modification was used: $5 \mathrm{ml}$ of GFP were collected after Sepharose 2 B gel filtration of 5 $\mathrm{ml}$ of PRP; GFP were centrifuged at $750 \mathrm{~g}$ for $15 \mathrm{~min}$ at $15^{\circ} \mathrm{C}$ and resuspended in $4 \mathrm{ml}$ of the eluant; the suspension contained about 200000 platelets per 
$\mathrm{mm}^{3}$; a single washing was sufficient for discarding the high molecular weight VIII VWF which is eluted with the GFP. The aggregation system contained $0.1 \mathrm{ml}$ of washed GFP, $0.1 \mathrm{ml}$ of various PPP dilutions $(1 / 2,1 / 10$, ${ }^{1 / 20}$ and $1_{140}$ ) and $10 \mu \mathrm{l}$ of ristocetin solution, with a final concentration of $1000 \mu \mathrm{g} / \mathrm{ml}$. On log-log paper the aggregation rates plotted against the various dilutions of added plasma were linear. By definition the aggregation rate determined with a pool of normal half-diluted plasma represents $100 \mathrm{U}$ per $100 \mathrm{ml}$ of VWF activity.

d) VIII AHF assay. A method previously reported [10] was used.

\section{Results}

\section{a. ADP Induced Aggregation}

The effect of diabetic PPP on the ADP induced aggregation of control subjects GFP is shown in the left part of Fig. 1. The group II diabetic PPP did not induce hyperaggregation in control subjects GFP with the exception of one case, while these patients exhibited the previously reported ADP induced hyperaggregation using PRP [3]; the same result was observed with group I and group III diabetic patients who did not exhibit hyperaggregation. This finding suggests, at least with the method used in our laboratory, that diabetic PPP has no clear effect on the ADP induced aggregation of control subject's GFP.

The rate of ADP induced aggregation on diabetic GFP in the absence of PPP as compared with control subjects GFP in the same conditions is shown in the right part of Fig. 1. The rate was normal or diminished in group I diabetics, elevated in group II and lowered in group III. These findings suggest that

Table 2. ADP and thrombin induced aggregation rate with diabetic $P R P$. Results are expressed as percentage compared with the aggregation rate with $P R P$ from control subjects

Group II Group III

Case ADP $0.5 \mu \mathrm{M}$ Thrombin Case ADP $0.5 \mu \mathrm{M}$ Thrombin

\begin{tabular}{rrrrrr}
\hline 7 & 414 & 148 & 13 & 87 & 101 \\
8 & 400 & 232 & 14 & 92 & 72 \\
9 & 280 & 192 & 15 & 88 & 137 \\
10 & 177 & 112 & 16 & 12 & 35 \\
11 & 583 & 115 & 17 & 43 & 40 \\
12 & 828 & 146 & 18 & 38 & 90 \\
\hline \multirow{2}{*}{ Mean } & 447 & 157 & Mean 60 & 79 \\
\hline
\end{tabular}
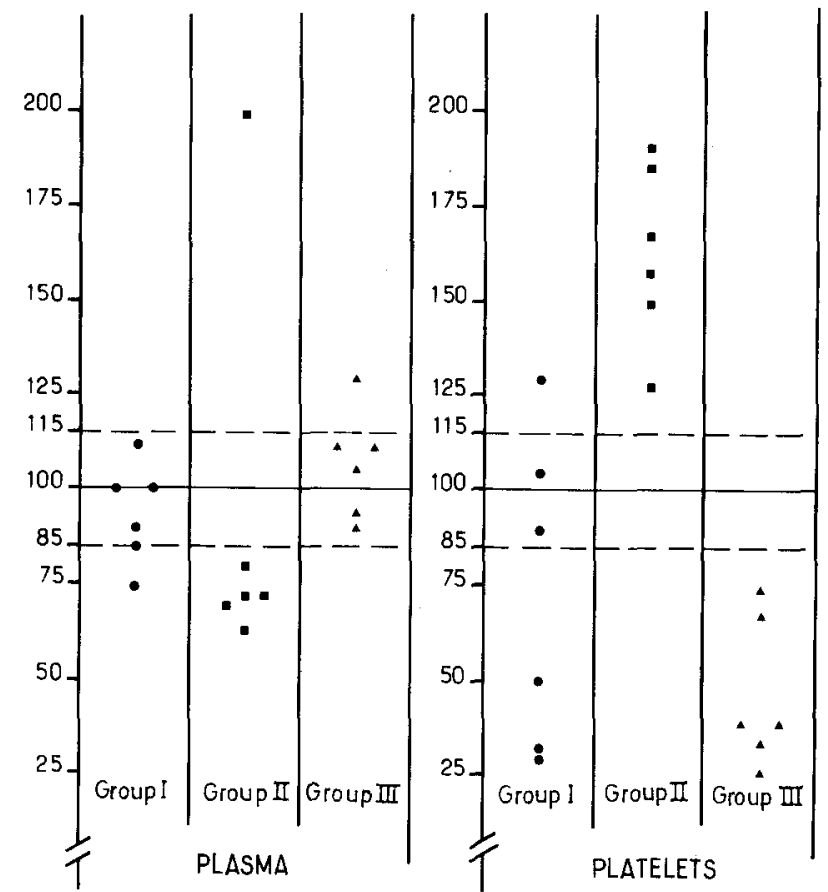

Fig. 1. Left part: effect of diabetic PPP on ADP induced aggregation of control subject's GFP. Results are expressed as a percentage, the value obtained with control subjects PPP representing $100 \pm 15 \%$. Right part: rate of ADP induced aggregation on diabetic GFP in the absence of PPP (gamma-globulins, fibrinogen and calcium chloride being used as cofactors), as compared with control GFP in the same conditions

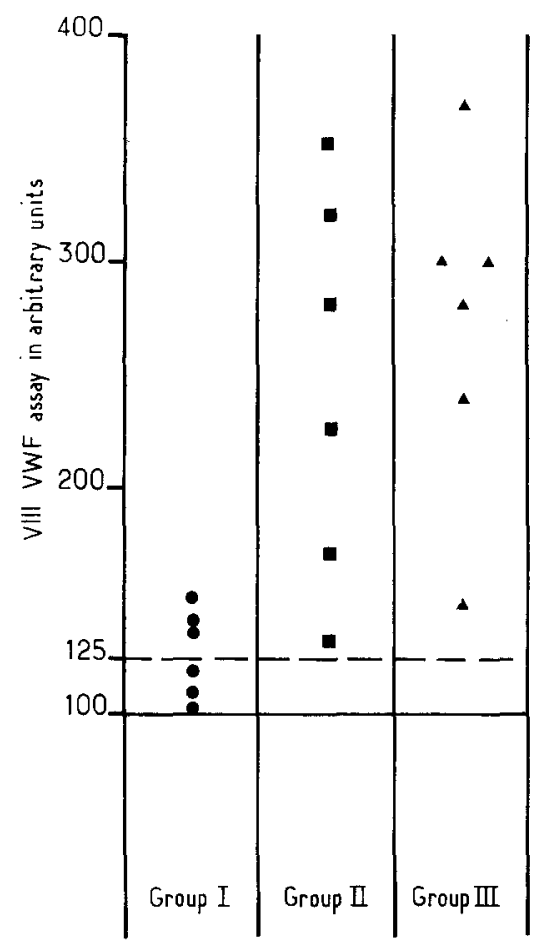

Fig. 2. VWF activity. Results are expressed in arbitrary units (see text) 
the ADP induced hyperaggregation previouslyreported in diabetics with severe retinopathy is related to a platelet and not to a plasma factor (with the exception of one out of the 6 cases in this series).

\section{b. Thrombin Induced Aggregation}

Using PRP, thrombin induced aggregation was determined in group II and group III diabetics. As shown in Table 2, two out of the 6 patients in group II exhibited hyperaggregation (cases 8 and 9); in two other cases (cases 7 and 12) the aggregation rate was slightly elevated, but this elevation may be related to ADP released and not to thrombin. In group III the aggregation rate was within normal limits, with the exception of two cases (cases 16 and 17) with a diminished rate.

Using GFP, results were similar.

\section{c. Assay of VWF and VIII AHF}

As shown in Fig. 2, VWF activity was normal or slightly elevated in group I diabetics and significantly elevated in group II and group III diabetics with retinopathy.

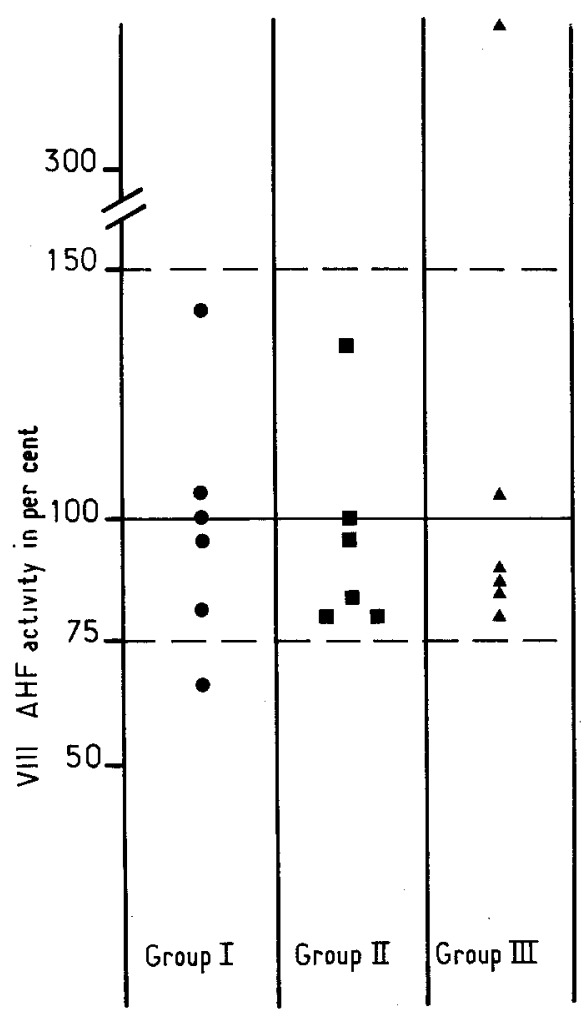

Fig. 3. AHF activity. Results are expressed as percentage of the control (mean of 20 normal subjects)
Table 3. VWF: AHF ratio. The average value in normal subjects is 1

\begin{tabular}{|c|c|c|c|c|c|}
\hline \multicolumn{2}{|c|}{ Group I } & \multicolumn{2}{|c|}{ Group II } & \multicolumn{2}{|c|}{ Group III } \\
\hline Case & Ratio & Case & Ratio & Case & Ratio \\
\hline 1 & 1.18 & 7 & 1.57 & 13 & 2.66 \\
\hline 2 & 0.73 & 8 & 2.82 & 14 & 3.75 \\
\hline 3 & 1.33 & 9 & 2.15 & 15 & 4.35 \\
\hline 4 & 1.29 & 10 & 2.59 & 16 & 0.90 \\
\hline 5 & 2.12 & 11 & 2.80 & 17 & 1.75 \\
\hline 6 & 1.56 & 12 & 3.47 & 18 & 2.66 \\
\hline Mean & 1.37 & Mean & 2.56 & Mean & 2.68 \\
\hline
\end{tabular}

VIII AHF activity was normal in the three groups, with the exception of one case in group III (Fig. 3).

As shown in Table 3, the VWF : AHF ratio was within normal limits in group I diabetics and elevated in group II and group III diabetics.

\section{Discussion}

Using platelets isolated by gel filtration these results suggest that ADP hyperaggregation in diabetics with severe retinopathy is related to a platelet factor. This finding is not in agreement with the data from Kwaan et al. [2] and from Leone et al. [11] who reported that hyperaggregation is due to a plasma factor. This discrepancy is difficult to explain; it might stem from the difference in the method employed for platelet separation, which involved repeated washing $[2,11]$. Isolation from plasma by washing appears to be too vigorous a method, since microscopic examination of platelets prepared with this technique has shown morphological alterations not observed with gel filtration [7]; it is thus possible that after the washing-separation technique, the presence of a platelet factor may have been missed. Recently Metcalf and Lyman [12] have shown that using polylysine as a platelet aggregating agent, the need for a plasma cofactor for platelet aggregation varied as a function of the conformational variation of the polymer; since in our studies ADP was used as an aggregating agent, variations in the conformation may not explain the discrepancy between our results and those of Kwaan and Leone. The existence of an abnormal plasma factor was not supported in the present study.

The platelet factor which interacts in ADP hyperaggregation may originate inside the cell and be released from its cytoplasmic pool by ADP, or may be related to a platelet membrane abnormality. In this study thrombin induced aggregation was in most cases within normal limits; as thrombin acts in releasing intra- 
platelet ADP after acting on a surface receptor, this finding suggests that the origin of the platelet factor is not inside the platelet, and hence is located at the plasma membrane, probably at the site of action of ADP. Its nature is still to be determined; it has been reported that in Glanzmann's disease ADP non-reactive platelets are associated with the absence of a platelet membrane glycoprotein [13]; in diabetic microangiopathy chemical alterations in the glomerular basement membrane are already known [14]; thus, the present findings suggest the hypothesis that the nature of the platelet factor may be related to some abnormality, possibly of the glycoproteins, in the platelet membrane.

The absence of ADP induced hyperaggregation in diabetics with proliferative retinopathy treated by hypophysectomy has been reported [3] and has so far no explanation. It is of interest to note that in the present study no hyperaggregability was found in the platelets isolated from blood obtained from these patients.

Beside the abnormalities of ADP induced aggregation, a high plasma level of VWF was observed in diabetics with severe retinopathy, while a normal level was observed in diabetics without retinopathy; this finding has not previously been reported. In patients with Von Willebrand's disease the low platelet retention to glass beads appeared to be better corrected with plasma from diabetics than from normals [15].

The VIII AHF level was within normal limits in our 3 groups of diabetics while a high level has previously been reported $[16,17]$.

An elevation of the VWF : AHF ratio was therefore noticed in diabetics with retinopathy. Such a dissociation between these two factors is an unexpected finding and its significance remains to be determined. Factor VIII is a high molecular weight complex of two proteins which may be dissociated into several oligomers by modifications of ionic strength [18] and which consists of VIII VWF and VIII AHF; these two factors may be complexed in a single molecule or may be two different and strongly associated molecules [18]; VIII VWF appears to be synthesised in endothelial cells, which do not elaborate VIII AHF $[19,20]$. It therefore seems that a dissociation between these 2 factors is possible, as was observed here.

The generally accepted scheme for primary haemostasis consists in platelet adhesion to collagen followed by release of several components including ADP. It has also been suggested that two non-dependent platelet-plasma-vessel systems may provide the white thrombus formation; the one including platelets, fibrinogen, ADP and collagen, the other including platelets, VWF and basement membrane [21]. Haemostatic abnormalities observed in diabetics with retinopathy may therefore be concerned with both systems.

Haemostatic abnormalities may be one of the mechanisms in the genesis of diabetic microangiopathy. If abnormalities in platelet aggregation take place in vivo, intracapillary microthrombi could occur and might be the cause of non-vascular areas recognised by fluorescein angiography in the early stage of retinopathy $[22,23]$; this would support the role of thrombosis as a factor of diabetic microangiopathy [24].

\section{References}

1. Heath, H., Brigden, W.D., Canever, J.V., Pollock, J., Hunter, P.R., Kelsey, J., Bloom, A.: Platelet adhesiveness and aggregation in relation to diabetic retinopathy. Diabetologia $\mathbf{7}$, $308-315$ (1971)

2. Kwaan, H.C., Colwell, J. A., Cruz, S., Suwanwela, N., Dobbie, J. G.: Increased platelet aggregation in diabetes mellitus. J. Lab. clin. Med. 80, 236-246 (1972)

3. Passa, P., Bensoussan, D., Levy-Toledano, S., Caen, J., Canivet, J.: Etude de l'agrégation plaquettaire au cours de la rétinopathie diabétique. Influence de l'hypophysectomie. Atherosclerosis 19, 277-285 (1974)

4. Howard, M.A., Firkin, B.G.: Ristocetin - a new tool in the investigation of platelet aggregation. Thrombos. Diathes. haemorrh. (Stuttg.) 26, 362-369 (1971)

5. Weiss, H. J., Rogers, J., Brand, H.: Defective ristocetin-induced platelet aggregation in Von Willebrand's disease and its correction by factor VIII. J. clin. Invest. 52, 2697-2707 (1973)

6. Weiss, H.J., Hoyer, L.W., Rickles, F. R., Varma, A., Rogers, $\mathrm{J} .:$ Quantitative assay of a plasma factor deficient in Von Willebrand's disease that is necessary for platelet aggregation. Relationship to factor VIII procoagulant activity and antigen content. J. clin. Invest. 52, 2708-2716 (1973)

7. Levy-Toledano, S., Rendu, F., Besson, P., Caen, J.: Aggregation of human gel filtered platelets. Requirement of apyrase and proteins. Rev. Europ. Et. Clin. Biol. 5, 513-518 (1972)

8. Tangen, O., Berman, H.J., Marfey, P.: Gel filtration. A new technique for separation of blood platelets from plasma. Thrombos. Diathes. haemorrh. (Stuttg.) 25, 268-278 (1971)

9. Born, G.V.R.: Aggregation of blood platelets by adenosine diphosphate and its reversal. Nature (Lond.) 194, 927-929 (1962)

10. Soulier, J.P., Larrieu, M. J.: Nouvelle méthode de diagnostic de l'hémophilie. Dosage des facteurs antihémophiliques A et B. Le Sang 24, 205-215 (1953)

11. Leone, G., Bizzi, B., Accoria, F., Boni, P.: Functional aspect of platelets in diabetes mellitus. In: Platelet aggregation and drugs (ed. L. Caprino, F. C. Rossi), pp. 49-61. New York: Acad. Press publish. 1974

12. Metcalf, L.C., Lyman, D.J.: The effect of conformational changes on the blood platelet reactivity of polylysine. Thrombosis Res. 5, 709-717 (1974)

13. Nurden, A. T., Caen, J.P.: An abnormal glycoprotein pattern in three cases of Glanzmann thrombasthenia. Brit. J. Haemat. 28, 255-262 (1974)

14. Beisswenger, P.J., Spiro, R. G.: Human glomerular basement membrane: chemical alteration in diabetes mellitus. Science 168, 596-598 (1970)

15. Odegaard, A. E., Skalhegg, B. A., Hellem, A. J.: Increased activity of "Anti Willebrand factor" in diabetic plasma. Thrombos. Diathes. haemorrh. (Stuttg.) 11, 27-37, (1964) 
16. Egeberg, O.: The blood coagulability in diabetic patients. Scand. J. clin. Lab. Invest. 15, 533-538 (1963)

17. Mayne, E.E., Bridges, J.M., Weaver, J. A.: Platelet adhesiveness, plasma fibrinogen and factor VIII levels in diabetes mellitus. Diabetologia 6, 436-440 (1970)

18. Van Mourik, K. A., Bouma, B.N., Labruyere, W.T., De Graal, S., Mochtar, I. A.: Factor VIII, series of homologous oligomers and a complex of two proteins. Thrombosis Res. 4, 155-164 (1974)

19. Hoyer, L. W., De Los Santos, R. P., Hoyer, J. R.: Antihemophilic factor antigen. Localisation in endothelial cells by immunofluorescence in microscopy. J. clin. Invest. 52, 2737-2744 (1973)

20. Jaffe, E. A., Hoyer, L. W., Nachman, R. L.: Synthesis of antihemophilic factor antigen by cultured human endothelial cells. J. clin, Invest. 52, 2757-2764 (1973)

21. Caen, J., Levy-Toledano, S.: Interaction between platelets and
Von Willebrand factor provides a new scheme for primary haemostasis. Nature New Biology 244, 159-160 (1973)

22. Kohner, E. N., Dollery, C.T., Paterson, J.W., Oakley, N.W., Fraser, T.R.: Arterial fluorescein studies in diabetic retinopathy. Diabetes 16, 1-10 (1967)

23. Caird, F.I., Pirie, A., Ramsell, T.G.: Diabetes and the eye, p. 24. Oxford, Blackwell: 1969

24. Bloodworth, J.M.B., Jr, Engerman, R. L., Davis, M.D.:Pathology of diabetic microangiopathy. In: Diabetes, Proc. 7th Congr. Intern. Diabetes Fed. (eds. R. R. Rodriguez, J. Vallance-Owen), pp. 804-819. Amsterdam: Excerpta Medica 1971

Prof. J. Canivet

Dept. of Endocrinology

Hôpital Saint-Louis

F-75475 Paris/Cedex 10

France 